\title{
Advanced asymptotic approaches and perturbation theory methods in the study of the mathematical model of single-frequency oscillations of a nonlinear elastic body
}

\author{
Sokil B. I. ${ }^{1}$, Pukach P. Ya. ${ }^{1,2}$, Sokil M. B. ${ }^{2}$, Vovk M. I. ${ }^{2}$ \\ ${ }^{1}$ Hetman Petro Sahaidachnyi National Army Academy, \\ 32 Heroes of Maidan Str., 79012, Lviv, Ukraine \\ ${ }^{2}$ Lviv Polytechnic National University, \\ 12 S. Bandera Str., 79013, Lviv, Ukraine
}

(Received 25 February 2020; Revised 11 March 2020; Accepted 31 March 2020)

\begin{abstract}
A combination of asymptotic methods in nonlinear mechanics with basic techniques of perturbation theory to study a mathematical model of the nonlinear oscillation system is proposed in the paper. The system under consideration describes the torsional vibrations of an elastic body, where its elastic properties are under the nonlinear law. The relationships presented as the ordinary differential equations are obtained due to the proposed procedure. Therefore, the main parameters of the single-frequency oscillations and the resonance conditions can be determined. There are proposed applications of the obtained results to the optimization problem concerning the processing equipment.
\end{abstract}

Keywords: mathematical model, single-frequency oscillations, nonlinear elasticity law, asymptotic method, amplitude, frequency.

2010 MSC: 34C15, 35L70

DOI: $10.23939 / \mathrm{mmc} 2020.02 .269$

\section{Introduction}

The main aim of the paper is the application of the nonlinear mechanics single-frequency method combined with the main ideas of the perturbations methods and the periodic Ateb-functions to the new classes of the dynamic systems. The considered mathematical models of the dynamic systems relate to the oscillation processes of the elastic bodies. That is why they can be described by the boundary problems for the nonlinear partial differential equations. The peculiarity of these models is the fact that in spite of the possibility of Fourier method application to construct the sets of the single-frequency solutions, the dynamic process of the systems is not isochronous. This process can be studied by the periodic Ateb-functions [1-4].

Our interest in this research is motivated by the possibility of creation of new materials with the elastic properties described by the nonlinear relationships, as well as by the ineffectiveness of the numerical simulation for their analysis. This ineffectiveness is especially exhibited while investigating such important phenomena as resonance. The question is even to describe the existence conditions of the resonance via the numerical simulation not to mention about its distinctive features. It is explained by the anisochronous unperturbed process. The example of torsional vibrations of the elastic body, where the elastic properties are close to the power law $\sigma=k \varepsilon_{1}^{\nu_{0}+1}$, where $\sigma$ is body elasticity, $\varepsilon_{1}$ is relative deformation, $\nu_{0}+1$ is the nonlinearity factor, $\nu_{0}>-1$ is analyzed to demonstrate the main issues of the general procedure. The ordinary differential equations that describe the main parameters of the single-frequency oscillations for the first approximation of the asymptotic solution are obtained.

\section{Bibliography and aim of the work}

Single- and multi-frequency oscillations of the one-dimensional mechanical systems, where the elastic properties of the material can be approximated by the linear or close to the linear elasticity law 
are well studied for the engineering calculations [5-7]. The principle of oscillation superposition is correct for these systems in case of the linear elasticity law. The asymptotic methods of the nonlinear mechanics [8-10] are effective to investigate the case of quasi-linear (close to the linear) elasticity law. Dynamic systems with strong nonlinear elasticity law possess the particularities that complicate the application of the mathematical methods. The particularities are the following: the principle of oscillations superposition is not accomplished for these dynamic systems; oscillations processes in these systems are characterized by dependence of the dynamic process period on amplitude; analytical solution of the unperturbed equations in the completed form can be obtained in the particular cases only; general analytical approach to study the perturbed systems analogs is unavailable.

Thus, the aim of the paper is to develop the procedure to study the dynamic processes of some classes of the systems with the distributed parameters. The mathematical models of these systems can be represented by the mixed problems for the close to the quasi-linear hyperbolic type equations. This type of boundary problems are considered under some restrictions, in particular, longitudinal or torsional vibrations of the elastic bodies [11-16], the dynamic processes of bodies "chain" interacting between them under the nonlinear forces [17], other nonlinear oscillations models [18]. To solve the pointed questions partially let us suppose: the nonlinear elastic features of the body material can be approximated by some power or close to its dependence. Then the application of the special periodic Ateb-functions $[19,20]$ allow constructing the solutions of the unperturbed analogs corresponding differential equations. The main ideas of perturbation methods [21,22] or the asymptotic methods of the nonlinear mechanics $[8,23]$ are effective for the systems with the small perturbed values.

\section{Mathematical model. General procedure}

Let us describe a mathematical model of the torsional oscillations of a nonlinear elastic body. To obtain this model one can consider "dynamic equilibrium" of conditionally preferred element of the elastic body in the constant cross-section with uniformly distributed mass along its length. It is wellknown [24], that an angle of torsion for this body $\phi(x, t)$ in the arbitrary section by the coordinate $x$ in the general case is described by dependence $\phi(x, t)=g(M), M$ is torsional moment. The function $g(M)$ is determined experimentally and can be approximated with the sufficient accuracy degree by the dependence $g(M)=G J(\partial \phi / \partial x)^{\nu+1}$, where $G$ is the modulus of the second order elasticity, $J$ is the inertia moment of the body cross-section with respect to the section neutral axis. The parameter $\nu$, approximating the nonlinear elastic properties of the body material in the wide deformation diapason, must satisfy the condition $\nu+1=\frac{2 m+1}{2 n+1}, m, n=0,1,2, \ldots$. The case of $\nu=0$ corresponds to the linear law. The main dynamic equation in this case for the elastic body element between the sections $x$ and $x+d x$ would be the following

$$
\rho J \phi_{t t}=\frac{\partial}{\partial x}\left(G J\left(\frac{\partial \phi}{\partial x}\right)^{\nu+1}\right),
$$

where $\rho$ is the body material density. Taking into account resisting forces with the small values and other dissipative forces, the obtained equation transforms to

$$
\phi_{t t}-\alpha^{2}\left(\phi_{x}\right)^{\nu} \phi_{x x}=\varepsilon f\left(\phi_{t}, \phi_{x}, \phi_{t x x}\right)
$$

with the boundary conditions

$$
\phi(0, t)=\varepsilon \varphi_{0}, \quad \phi(l, t)=-\varepsilon \varphi_{0} .
$$

In the equation (1), the function $\phi(x, t)$ is the torsion angle of the elastic body, $\alpha^{2}=(\nu+1) \frac{G}{\rho}$, $\varepsilon$ is the small parameter, indicating that the maximum value of the right-hand side of the equation (2) (known analytic function $\varepsilon f\left(\phi_{t}, \phi_{x}, \phi_{t x x}\right)$ ) is the small value in comparison with the maximum value of the second term in the left-hand side of the equation, $\varphi_{0}$ is the known constant $\left( \pm \varepsilon \varphi_{0}\right.$ are the torsion angles of the ends of the body with the length $l$ ). That is why the unperturbed analog of 
the equation (1), i.e. the equation $\Psi_{t t}-\alpha^{2}\left(\Psi_{x}\right)^{\nu} \Psi_{x x}=0$ is of a hyperbolic type one. Therefore, the periodic solution [11] exists under the homogeneous first-type boundary conditions. The solution of the set problem with the perturbed boundary conditions, taking into account the restrictions in the right sides in the relationships (1) and (2), one can find as [9]

$$
\phi(x, t)=\Psi(x, t)+\theta(x, t)
$$

where the function $\theta(x, t)$ is the solution of the differential equation $\theta_{x x}(x, t)=0$, satisfying the boundary conditions $\theta(0, t)=\varepsilon \varphi_{0}, \theta(l, t)=-\varepsilon \varphi_{0}$. It is easy to obtain $\theta(x, t)=\varepsilon \varphi_{0}-\varepsilon \frac{2 \varphi_{0}}{l} x$. Then the function $\phi(x, t)$ is the solution of the nonlinear equation

$$
\Psi_{t t}-\alpha^{2}\left(\Psi_{x}\right)^{\nu} \Psi_{x x}=\varepsilon f\left(\Psi_{t}, \Psi_{x}-\varepsilon \frac{2 \varphi_{0}}{l}, \Psi_{t x x}\right)
$$

and satisfies the homogeneous boundary conditions

$$
\Psi(0, t)=0, \quad \Psi(l, t)=0 .
$$

The main ideas of the perturbations methods can be applied to the study of the considered dynamic processes due to the restrictions of the right side of the equation (1) and the boundary conditions for the function $\phi(x, t)$. They are the most effective in case when the unperturbed analogs of the corresponding boundary problems allow to construct the solution in the closed form. There is the solution of the equation $\phi_{t t}-\alpha^{2}\left(\phi_{x}\right)^{\nu} \phi_{x x}=0$ under the homogeneous boundary conditions (5). In spite of the equation is nonlinearity, the separation variables can be realized, that means that solution can be found as

$$
\phi(x, t)=\Phi(x) \cdot T(t) .
$$

To find the unknown functions $\Phi(x)$ and $T(t)$ one can obtain, using (6), the ordinary nonlinear differential equations

$$
\begin{gathered}
\frac{d^{2} \Phi}{d x^{2}}\left(\frac{d \Phi}{d x}\right)^{\nu}+\lambda \Phi(x)=0, \\
\frac{d^{2} T}{d t^{2}}+\alpha^{2} \lambda T^{\nu+1}(t)=0,
\end{gathered}
$$

where the unknown parameter $\lambda$ in (8) is determined in such a way, the boundary conditions (5) is true. Thus, function $\Phi(x)$ must satisfy the following conditions

$$
\Phi(0)=\Phi(l)=0 .
$$

Linear independent solutions of the equation (7) are represented by the periodic Ateb-functions

$$
\Phi(x)=\Phi_{0}\left\{\begin{array}{l}
\operatorname{sa}\left(1, \frac{1}{\nu+1},\left(\lambda_{k} \frac{\nu+2}{2 \Phi_{0}^{\nu}}\right)^{\frac{1}{\nu+2}} x\right), \\
\operatorname{ca}\left(1, \frac{1}{\nu+1},\left(\lambda_{k} \frac{\nu+2}{2 \Phi_{0}^{\nu}}\right)^{\frac{1}{\nu+2}} x\right),
\end{array}\right.
$$

where $\Phi_{0}$ is constant. One can obtain from (9) and (10) eigenvalues and their corresponding set of the boundary problem solutions for the linear variable $\Phi(x)$ in the following form

$$
\Phi(x)=\Phi_{0} \mathrm{sa}\left(1, \frac{1}{\nu+1}, \Pi_{x} \frac{k}{l} x\right) .
$$


Value $\Pi_{x}=\Pi_{x}\left(1, \frac{1}{\nu+1}\right)$ is period on the argument $\Pi_{x} \frac{k}{l} x$ of used Ateb-function, $k=1,2,3, \ldots$ in dependence (11). Solutions set of the equation describing time changes in torsional oscillations of the elastic body can be found similarly

$$
T(t)=T_{0}\left\{\begin{array}{l}
\operatorname{ca}\left(\nu+1,1,\left(\frac{\nu+2}{2} \alpha^{2} \lambda_{k} T_{0}^{\nu}\right)^{\frac{1}{2}} t\right), \\
\operatorname{sa}\left(\nu+1,1,\left(\frac{\nu+2}{2} \alpha^{2} \lambda_{k} T_{0}^{\nu}\right)^{\frac{1}{2}} t\right),
\end{array}\right.
$$

where $T_{0}$ is the arbitrary constant. Substituting values that coordinate with the boundary conditions instead of parameter $\lambda_{k}$ into (12) one can obtain

$$
T(t)=T_{0}\left\{\begin{array}{l}
\operatorname{ca}\left(\nu+1,1, \omega_{k}\left(a_{k} t\right)\right), \\
\operatorname{sa}\left(\nu+1,1, \omega_{k}\left(a_{k} t\right)\right) .
\end{array}\right.
$$

Hence, the set of single-frequency solutions, describing the unperturbed torsional oscillations of the elastic body consists of the functions

$$
\phi_{k}(x, t)=a \operatorname{sa}\left(1, \frac{1}{\nu+1}, \Pi_{x} \frac{k}{l} x\right) \operatorname{ca}\left(\nu+1,1, \omega_{k}(a) t+\theta_{0}\right),
$$

where $\omega_{k}(a)=\alpha a^{\frac{\nu}{2}}\left(\frac{k \Pi_{x}}{l}\right)^{\frac{\nu+2}{2}}, a=\Phi_{0} T_{0}$ is the corresponding mode amplitude of the torsional oscillations, $\theta_{0}$ is their initial phase.

Remark. The initial conditions for the original system (1), (2) must satisfy the existence of singlefrequency oscillations mode, close to one of the "dynamic equilibrium" forms of the system. This question is not discussed in the paper.

\section{Single-frequency oscillations}

Single-frequency torsional oscillations of the linear elastic body are the special case of the obtained relationships (13) if $\nu=0$. There are fundamental differences between this special case and obtained general nonlinear case described by the dependence (13): a) eigenfrequency spectrum does not depend on amplitude for the linear torsional oscillations, but it depends for the nonlinear case; b) resonant torsional oscillations of the elastic bodies with material satisfying the nonlinear elasticity law, are different in principle from the oscillations with the linear elasticity law. These problems can be the subject under separate study. By the way, the system of functions

$$
\Phi_{k}(x)=\left\{\mathrm{sa}\left(1, \frac{1}{\nu+1}, \Pi_{x} \frac{k}{l} x\right)\right\}
$$

describing forms of single-frequency torsional oscillations, possesses the orthonormalized property

$$
\int_{0}^{l} \Phi_{m}(x) \Phi_{n}(x) d x=\delta_{m n} P
$$

where $\delta_{m n}$ is Kronecker delta, and $P=\frac{\nu+2}{3 \nu+4} l$ for the considered boundary conditions. This property essentially simplifies the perturbed problem solving, that is to find the approximate analytic solution of the equation (1) under the inhomogeneous boundary conditions (2). There are two main analytic approaches: the first is to represent the solution of considered boundary problem as the asymptotic series form, the sense of the second is to extend the main idea of Bubnov-Galerkin and Van der Pol methods to the new class of the dynamic systems $[23,25,26]$. The first method needs cumbersome mathematical calculations even for the most simple form of the right sides of the equation (4). Therefore, we will 
discuss the second method. Single-frequency oscillations principle easier implements this method in the nonlinear systems with multi-degree-of-freedom and distributed parameters. In accordance with the main idea, the perturbed oscillations for the first approximation of the asymptotic solution can be treated in the same form as the unperturbed oscillations, but the difference is that amplitude and frequency of the process are slowly changeable time functions. So, let us find the solution of the boundary problem (4), (5) in the following form

$$
\phi(x, t)=a(t) \Phi_{1}(x) \mathrm{ca}\left(\nu+1,1, \omega_{1}(a(t)) t+\theta(t)\right) .
$$

The task is to determine the laws of changing functions $a(t), \theta(t)$, satisfying the considered mathematical model of the elastic body torsional oscillations with the needed degree of accuracy. Differentiation with respect to time of the dependence (14), taking into account the main ideas of Bubnov-Galerkin and Van der Pol methods, derives the following equations

$$
\begin{gathered}
\frac{d a}{d t} \operatorname{ca}\left(\nu+1,1, \psi_{1}\right)-\frac{2 a}{\nu+2} \frac{d \theta}{d t} \operatorname{sa}\left(1, \nu+1, \psi_{1}\right)=0 \\
\frac{\partial^{2} \phi}{\partial t^{2}}=-\frac{2 \Phi_{1}(x)}{\nu+2} \frac{d a}{d t}\left(\omega_{1}(a)+a \frac{d \omega_{1}(a)}{d a}\right) \mathrm{sa}\left(1, \nu+1, \psi_{1}\right) \\
+\frac{2 X_{1}}{\nu+2} \frac{d a}{d t} \omega_{1}\left(\omega_{1}(a)+\frac{d \theta}{d t}\right) \mathrm{ca}^{\nu+1}\left(\nu+1,1, \psi_{1}\right), \quad \psi_{1}=\omega_{1}(a) t+\theta
\end{gathered}
$$

The dependences (15), (16) and equation (4) determine in total unknown functions and by the following differential equations

$$
\begin{aligned}
& \dot{a}=\varepsilon \frac{\mathrm{sa}\left(1, \nu+1, \psi_{1}\right) f_{1}^{*}\left(a, \psi_{1}\right)}{\omega_{1}(a) P}, \\
& \dot{\theta}=\varepsilon \frac{(\nu+2) \mathrm{ca}\left(\nu+1,1, \psi_{1}\right) f_{1}^{*}\left(a, \psi_{1}\right)}{2 a \omega_{1}(a) P},
\end{aligned}
$$

where

$$
f_{1}^{*}\left(a, \psi_{1}\right)=\frac{1}{l} \int_{0}^{l} f\left(a \Phi_{1}(x) \operatorname{ca}\left(\nu+1,1, \psi_{1}\right), \ldots,-\frac{2 a}{\nu+2} \omega_{1} \Phi_{1}(x) \operatorname{sa}\left(1, \nu+1, \psi_{1}\right)\right) \Phi_{1}(x) d x .
$$

\section{Analysis of torsional oscillations mathematical model}

The differential equations system (17) is quite complicated for the quantitative and qualitative analysis of the nonlinear elastic body torsional oscillations. It is reasonable to simplify the system for the practical implementation of the obtained results. Let us advance the following arguments: if the right side of the autonomous differential equation (2) is proportional to the small parameter, and the boundary conditions are of the autonomous type, then the single-frequency process amplitude changes negligibly during one oscillation period. This peculiarity forms the basis for the averaging over the oscillation phase of the right sides, i.e.

$$
\begin{aligned}
& \dot{a}=\frac{\varepsilon}{2 \Pi_{T} P l \omega_{1}(a)} \int_{0}^{2 \Pi_{T}} \int_{0}^{l} \mathrm{sa}\left(1, \nu+1, \psi_{1}\right) \Phi_{1}(x) f_{1}\left(a, x, \psi_{1}\right) d x d \psi_{1}, \\
& \dot{\psi}=\omega_{1}(a)+\frac{\varepsilon(\nu+2)}{4 a \Pi_{T} l P \omega_{1}(a)} \int_{0}^{2 \Pi_{T}} \int_{0}^{l} \mathrm{ca}\left(\nu+1,1, \psi_{1}\right) \Phi_{1}(x) f_{1}\left(a, x, \psi_{1}\right) d x d \psi_{1},
\end{aligned}
$$

where $2 \Pi_{T}=2 \Pi(1, \nu+1)$ is the oscillation phase $\psi_{1}$ period. The following statement can be proposed as conclusion: the first approximation of the elastic body dynamic process with the boundary problem (1), 
(2), as the mathematical model of torsional oscillations is described by the following dependence

$$
\phi_{1}(x, t)=a \mathrm{sa}\left(1, \frac{1}{\nu+1}, \Pi_{x} \frac{k}{l} x\right) \text { ca }\left(\nu+1,1, \psi_{1}\right)+\varepsilon \varphi_{0}-\varepsilon \frac{2 \varphi_{0}}{l} x,
$$

where parameters $a, \psi_{1}$ are connected by the differential equations (18). Let us consider the nonlinear single-frequency body oscillations under the condition that the resistant force is proportional to the speed with $2 \nu_{1}+1$ degree as the example. The right side of the differential equation (1) in this case is the following

$$
\varepsilon f\left(\phi_{t}, \phi_{x}, \phi_{t x x}\right)=\varepsilon\left(\beta_{1}\left(\phi_{t}\right)^{2 \nu_{1}+1}\right),
$$

where $\beta_{1} \nu_{1}$ are foregone constants. To find time change of the amplitude and frequency of the torsional oscillations with respect to the dependences (18), (19) one can obtain

$$
\begin{aligned}
& \dot{a}=\frac{\varepsilon \beta_{1}}{\Pi_{T} \Pi_{x} \rho \omega_{1}(a)}\left(\frac{2 a \omega(a)}{(\nu+2)}\right)^{2 \nu_{1}+1} \frac{\left(\Gamma\left(\frac{2\left(\nu_{1}+1\right)+1}{2}\right)\right)^{2} \Gamma\left(\frac{\nu+1}{\nu+2}\right) \Gamma\left(\frac{1}{\nu+2}\right)}{\Gamma\left(\frac{2\left(\nu_{1}+1\right)+1}{2}+\frac{\nu+1}{\nu+2}\right) \Gamma\left(\frac{2\left(\nu_{1}+1\right)+1}{2}+\frac{1}{\nu+2}\right)}, \\
& \dot{\psi}=\alpha a^{\frac{\nu}{2}\left(\frac{\Pi_{x}}{l}\right)^{\frac{\nu+2}{2}}} .
\end{aligned}
$$

Dependence of torsional oscillations frequency on amplitude with respect to the equations (20) is demonstrated in Fig. 1.

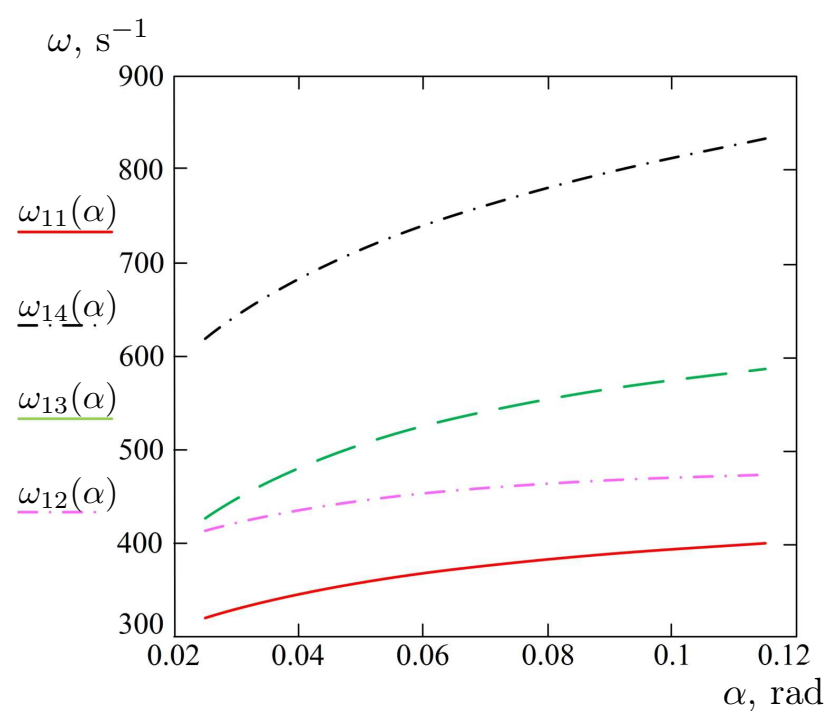

Fig. 1. Dependences of torsional oscillations frequency on amplitude.

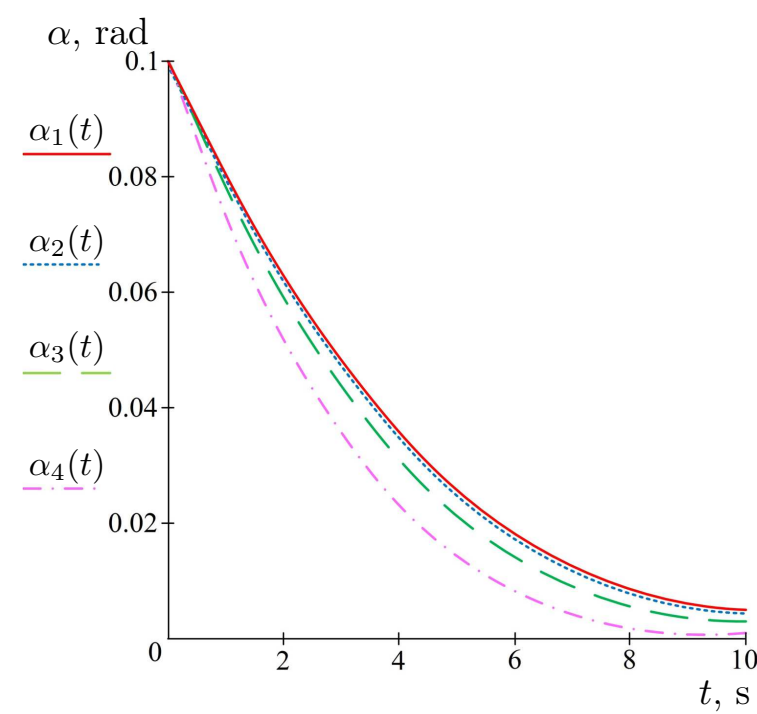

Fig. 2. Dependences of the amplitude on time.

Represented dependences are obtained in four cases of the nonlinear elastic bodies properties respectively with four frequencies on the figure: frequency $\omega_{11}(a)$ corresponds to the body with the properties $G=5.6 \cdot 10^{8} \mathrm{~Pa}, \nu=2 / 5$; frequency $\omega_{12}(a)$ corresponds to the body with the properties $G=1.5 \cdot 10^{8} \mathrm{~Pa}$, $\nu=2 / 15$; frequency $\omega_{13}(a)$ corresponds to the body with the properties $G=1.3 \cdot 10^{8} \mathrm{~Pa}, \nu=2 / 9$; frequency $\omega_{14}(a)$ corresponds to the body with the properties $G=1.8 \cdot 10^{8} \mathrm{~Pa}, \nu=4 / 9$. Time change of torsional oscillations amplitude $a_{i}(t), i=1,2,3,4$ is shown in Fig. 2 for the same four cases.

Results that are obtained considering the torsional oscillations mathematical model can be used as basis for the resonant oscillations study. Discussed oscillations mode can be subject of separate investigation. Let us study their existence conditions, considering periodic by phase external pertur- 
bation. The classic condition is true in case of the main resonance: eigenoscillations and perturbed oscillations periods must be equal (close to equal), that is $\frac{2 \pi}{\mu}=\frac{2 \Pi_{T}}{\omega(a)}$, where $\mu$ is frequency of the external periodic perturbation. Therefore, the resonant torsional oscillations appear under condition, when their amplitude converges to the foregone value

$$
a^{*}=\left(\frac{\Pi_{T} \mu}{\alpha \pi}\left(\frac{l}{\Pi_{x}}\right)^{\frac{\nu+2}{2}}\right)^{\frac{2}{\nu}} .
$$

This result is important while analyzing the dynamic oscillations modes, describing the considered mathematical models.

\section{Conclusions}

In this paper, a procedure to study the mathematical model of elastic body oscillations, which combines asymptotic approaches and perturbations methods is proposed (elastic properties of the body material are described by close to power elasticity law). There is shown that the dynamic process in these systems differs in comparison with that in the linear systems. Firstly, there is the dependence of eigenfrequency on amplitude. In particular, the less value of the eigenoscillations frequency corresponds to the greater oscillations amplitude values. Just the opposite statement is true in the case. Concerning the damped oscillations, one can see that the amplitude decrease does not essentially depend on the nonlinear elastic properties of the body material. The main idea of the paper can be used to study the dynamic processes of some other nonlinear oscillation systems classes. The obtained results can be used in problems of synthesis and optimization of parameters, ensuring running characteristics of processing equipment.

[1] Cveticanin L. Strong Nonlinear Oscillator - Analytical Solutions. Mathematical Engineering. Springer (2018).

[2] Cveticanin L. Period of vibration of axially vibrating truly nonlinear rod. Journal of Sound and Vibration. 374, 199-210 (2016).

[3] Cveticanin L., Pogany T. Oscillator with a sum of non-integer order non-linearities. Journal of Applied Mathematics. 2012, Article ID 649050, 20 pages (2012).

[4] Gendelman O., Vakakis A. F. Transitions from localization to nonlocalization in strongly nonlinear damped oscillators. Chaos, Solitons and Fractals. 11 (10), 1535-1542 (2000).

[5] Mitropol'skii Yu. A. On construction of asymptotic solution of the perturbed Klein-Gordon equation. Ukr. Math. J. 47 (9), 1378-1386 (1995).

[6] Mitropol'skii Yu. A., Limarchenko O. S. On asymptotic approximations for slow wave processes in nonlinear dispersive media. Ukr. Math. J. 50 (3), 408-424 (1998).

[7] Oleynik O. A. Lectures on partial differential equations. Moscow, Binomial (2005), (in Russian).

[8] Andrianov I. V. Danishevskyi V. V., Ivankov A. O. Asymptotic methods in the theory of vibrations of beams and plates. Dnepropetrovsk, Pridneprovsk State Academy of Civil Engineering and Architecture (2010), (in Russian).

[9] Mitropolskii Yu. A., Moseenkov B. I. Asymptotic solutions of partial differential equations. Kyiv, Vyshcha Shkola (1976), (in Russian).

[10] Pukach P. Ya., Kuzio I. V. Resonance phenomena in quasi-zero stiffness vibration isolation systems. Naukovyi Visnyk Natsionalnoho Hirnychoho Universytetu. 3, 62-67 (2015).

[11] Myshkis A. D., Filimonov A. M. Periodic oscillations in nonlinear one-dimensional continuous media. Proceedings of the IX International Conference on nonlinear oscillations. Part 1, 274-276 (1984), (in Russian). 
[12] Pukach P. Ya., Kuzio I. V., Nytrebych Z. M., Ilkiv V. S. Analytical methods for determining the effect of the dynamic process on the nonlinear flexural vibrations and the strength of compressed shaft. Naukovyi Visnyk Natsionalnoho Hirnychoho Universytetu. 5, 69-76 (2017).

[13] Pukach P. Ya., Kuzio I. V., Nytrebych Z.M., Ilkiv V.S. Asymptotic method for investigating resonant regimes of non-linear bending vibrations of elastic shaft. Naukovyi Visnyk Natsionalnoho Hirnychoho Universytetu. 1, 68-73 (2018).

[14] Pukach P. Ya. Investigation of bending vibrations in Voigt-Kelvin bars with regard for nonlinear resistance forces. J. Math. Sci. 215 (1), 71-78 (2016).

[15] Pukach P. Y. Qualitative Methods for the Investigation of a Mathematical Model of Nonlinear Vibrations of a Conveyer Belt. J. Math. Sci. 198 (1), 31-38 (2014).

[16] Pukach P. Ya., Kuzio I. V. Nonlinear transverse vibrations of semiinfinite cable with consideration paid to resistance. Naukovyi Visnyk Natsionalnoho Hirnychoho Universytetu. 3, 82-86 (2013), (in Ukrainian).

[17] Filimonov A. M. Continual and discrete models of bounded one-dimensional media in viscoelasticity. Journal of Applied Mathematics and Mechanics. 61 (2), 275-285 (1997).

[18] Myshkis A.D., Filimonov A. M. Continuous solutions of hyperbolic systems of quasilinear equations with two independent variables. Nonlinear analysis and nonlinear differential equations. Moscow, Fizmatlit (2003), (in Russian).

[19] Senik P. M. Inversion of the incomplete beta function. Ukr. Math. J. 21 (3), 271-278 (1969).

[20] Nazarkevych M. Investigation of Beta- and Ateb-function dependencies. Bulletin of the National University "Lviv Polytechnic".732: Computer Science and Information Technology, 207-216 (2012) (in Ukrainian).

[21] Nayfeh A. H. Perturbation methods. New York, Wiley-Interscience (1973).

[22] Maslov V.P. Asymptotic methods and perturbation theory. Moscow, Nauka (1988), (in Russian).

[23] Sokil B. I. Periodic Ateb-functions in the study of single-frequency solutions of some wave equations. Proceedings of Shevchenko Scientific Society. 1, 588-592 (1997), (in Ukrainian).

[24] Pisarenko G.S., Kvitka O. L., UmanskyE.S. Resistance of materials. Kyiv, Vyshcha shkola (2004), (in Ukrainian).

[25] Sokil B., Senyk A., Sokil M., Andrukhiv A., Kovtonyuk M., Gromaszek K., Ziyatbekova G., Turgynbekov Y. Mathematical models of dynamics of friable media and analytical methods of their research. Przeglad Elektrotechniczny. 95 (4), 74-78 (2019).

[26] Lyashuk O., Vovk Y., Sokil B., Klendii V., Ivasechko R., Dovbush T. Mathematical model of a dynamic process of transporting a bulk material by means of a tube scraping conveyor. Agricultural Engineering International: CIGR Journal. 21 (1), 74-81 (2019). 


\title{
Застосування асимптотичних підходів та методів теорії збурень до дослідження математичної моделі одночастотних коливань нелінійно пружного тіла
}

\author{
Сокіл Б. І. ${ }^{1}$, Пукач П. Я. ${ }^{1,2}$, Сокіл М. Б. ${ }^{2}$, Вовк М. І. ${ }^{2}$ \\ ${ }^{1}$ Національна академія сухопутних війсък імені гетъмана Петра Сагайдачного, \\ вул. Героїв Майдану, 32, 79012, Львів, Украӥна \\ ${ }^{2}$ Національний університет "Львівсъка політехніка", \\ вул. С. Бандери, 12, 79013, Львів, Україна
}

У роботі проілюстровано можливості поєднання асимптотичних методів нелінійної механіки та основних положень теорії збурень для дослідження математичної моделі нелінійної коливальної системи. Розглянута система описує крутильні коливання пружного тіла, пружні властивості якого описуються нелінійним законом. За допомогою розробленої у роботі методики дослідження динамічної системи отримано співвідношення у вигляді звичайних диференціальних рівнянь для визначення основних параметрів одночастотних коливань та умови виникнення резонансу. Вказано на практичні застосування отриманих результатів у задачах оптимізації параметрів технологічного обладнання.

Ключові слова: математична модель, одночастотні коливання, нелінійний закон пружності, асимптотичний метод, амплітуда, частота. 